which sets the disease process in motion in the susceptible patient (Lehr, 1972).

In each of our three cases a hypersensitivity vasculitis seemed to develop within seven days of starting alclofenac therapy. This suggests therefore that alclofenac should be included in the list of drugs known to be capable in initiating a vasculitis. Prompt withdrawal of the drug at the first sign of reaction may reduce the risk of inducing a chronic vascular disorder.

We thank Dr. Colin Berry from the pathology department and Kevin Fitzpatrick from the anatomy department for their help with this paper.

Requests for reprints should be addressed to H.C.B.

\section{References}

Aroutyunov, V. (1969). Dermatologica, 138, 75.

Aylward, M., and Davies, D. B. (1972). British fournal of Clinical Practice, 26, 517 .

Aylward, M. (1973). British fournal of Clinical Practice, 27, 255.

Bjornberg, A., and Gisslen, H. (1965). Lancet, 2, 982.

Citron, B. P., et al. (1970). New England Fournal of Medicine, 283, 1003.

Dalgleish, P. G. (1952). Lancet, 2, 319.
Dewar, H., and Peaston, M. (1964). British Medical fournal, 2, 609.

Germuth, F. G., and Rodriguez, E. (1973). Immunopathology of the Renal Glomerulus, p. 170. Boston, Little Brown.

Gibson, P. C., and Quinlan, J. T. (1945). Lancet, 2, 108.

Goldman, A., and Braman, S. (1972). Chest, 62, 71 .

Goldman, A., and Braman, S. (1972). Chest, 62, 71.

Gutierrez, R., et al. (1967). Revista Espaniola de Cardiologia, 20, 216. 235,897 .

Hodge, P. R., and Lawrence, J. R. (1957). Medical Fournal of Australia, 1, 640.

Jarzobski, J., et al. (1970). American Heart fournal, 79, 116.

Knowles, H. C., and Kaplan, S.A., (1953). Archives of Internal Medicine, 92, 189.

Koff, R. S., Widrich, W., and Robbins, A. N. (1973). New England fournal of Medicine, 288, 946 .

Lehr, D. (1972). Fournal of Clinical Pharmacology, 12, 181.

Mansel-Jones, D. (1974). British Medical fournal, $1,160$.

Miller, H. G., and Nelson, M. G. (1945). Lancet, 2, 200.

Rich, A. R. (1945). Bulletin of 7ohn Hopkins Hospital, 77, 43.

Rose, G. A., and Spencer, H. (1957). Quarterly fournal of Medicine, 26, 43.

Sloan, J., and Weaver, J. (1968). Irish fournal of Medical Science, 7th series, 1,505 .

Slocumb, C. H., Polley, H. F., and Ward, L. E. (1957). Proceedings of the Mayo Clinic, 32, 227 .

Mayo Clinic, 32, Procedings of the Royal Society of Medicine, 55, 20.
Symmers, W. (1962). Proced

Symmers, W. (1962). Proceedings of the Royal Society of $M$.
Szwarc, M., and Kaminski, E. (1971). Gruzlica, 39, 135.

Van Wyk, J., and Hoffmann, C. (1948). Archives of Internal Medicine, 81, 605 Wharton, C. F., and Pietroni, R. (1974). British Medical fournal, 2, 331.

Winkelmann, R. K., and Winston, W. B. (1964). Medicine, 43, 59.

Winton, S. S., and Nora, E. D. (1955). American fournal of Medicine, 18, 66. Zanini, S., and Porciello, P. (1970). Fracastoro, 63, 117.

Zeek, P. M. (1953). New England Fournal of Medicine, 248, 764.

\title{
Absorption of Effervescent Aspirin during Migraine
}

\author{
G. N. VOLANS
}

British Medical fournal, 1974, 4, 265-269

\begin{abstract}
Summary
The absorption of effervescent aspirin was studied in 42 patients during acute attacks of migraine. When compared with normal controls and with themselves between attacks 19 out of the 42 patients showed impairment of absorption. Impairment of absorption seemed to correlate with the severity of the headache and the gastrointestinal symptoms at the time of treatment but not with the duration of the attack or with the type of migraine. This study probably underestimated the prevalence of impairment of absorption in migraine attacks, and it is concluded that the treatment of acute migraine symptoms by oral drugs should use those formulations which are rapidly absorbed under normal conditions.
\end{abstract}

\section{Introduction}

Gastrointestinal symptoms have been recognized as a major characteristic of migraine since the second century A.D. (Critchley, 1967) and they remain one of the current clinical criteria for diagnosis of migraine (World Federation of Neurology, 1970). It has also been suggested that the gastrointestinal disturbances in migraine could impair the absorption of drugs given orally as treatment during the acute attack (Nimmo,

Princess Margaret Migraine Clinic, London EC1M 6DX

G. N. VOLANS, M.B., M.R.C.P., Migraine Trust Research Fellow (Present appointment: Lecturer in Clinical Pharmacology, St. Bartholomew's Hospital Medical College, London)
1973), and to overcome this many of the drugs used in migrainmay be administered other than as oral preparations (Wilkine son, 1971). Clinical trials on the administration of ergotamine tartrate (Graham et al., 1960; Sutherland and Eadie, 1961) provide evidence that the efficacy of treatment is related to the route of administration. The relatively poor efficacy of the oral route could be due to impaired absorption of the drug by the gastrointestinal tract. There are at present no methods capable of measuring ergotamine tartrate blood levels from therapeutic doses, however, and none of the studies have been directly concerned with assessment of gastrointestinal symptoms and their relationship to absorption of the drug. This paper reports the gastrointestinal symptoms and the absorption of effervescent aspirin in a group of patients treated during acute migraine attacks.

\section{Patients and Methods}

Forty-two patients suffering from acute headaches were studied at the Princess Margaret Migraine Clinic. All gave informed consent to the investigation. The diagnoses were made according to the criteria of the World Federation of Neurology (1970) and were confirmed by at least one other member of the clinic medical staff. Patients were not included in the study if there was any evidence of other illness, any history of dyspepsia, or if analgesic drugs had been taken within 24 hours before arrival at the clinic. Twenty control subjects were taken from the hospital medical, nursing, and administrative staffs. None had a history of headaches or gastrointestinal disease. The controls were not deliberately matched with the patients but the groups were of similar age, weight, and sex distribution (table I).

Aspirin was given as a single dose of three tablets containing a total of $900 \mathrm{mg}$ acetylsalicylic acid in an effervescent base equivalent to $1,800 \mathrm{mg}$ sodium bicarbonate and $1,200 \mathrm{mg}$ anhydrous citric acid (Claradin) dissolved in $150 \mathrm{ml}$ of water. 
TABLE I-Comparison between Groups of Age, Sex, and Weight

\begin{tabular}{|c|c|c|c|c|c|}
\hline & \multirow{2}{*}{$\begin{array}{c}\text { No. of } \\
\text { Subjects }\end{array}$} & \multicolumn{2}{|c|}{ Sex } & \multirow{2}{*}{$\begin{array}{c}\text { Mean Age } \\
\text { ( } \pm \text { S.D. }) \\
\text { (Years) }\end{array}$} & \multirow{2}{*}{${ }_{( \pm \underset{(\mathbf{k g})}{\text { Mean Weight }}}^{\text {S.D. }}$} \\
\hline & & M. & F. & & \\
\hline 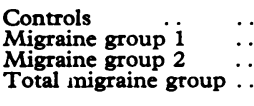 & $\begin{array}{l}20 \\
22 \\
20 \\
42\end{array}$ & $\begin{array}{r}11 \\
11 \\
6 \\
17\end{array}$ & $\begin{array}{r}9 \\
11 \\
14 \\
25\end{array}$ & $\begin{array}{l}29 \cdot 3 \pm 8 \cdot 1 \\
36 \cdot 1 \pm 12 \cdot 7 \\
37 \cdot 4 \pm 11 \cdot 4 \\
36 \cdot 8 \pm 12 \cdot 1\end{array}$ & $\begin{array}{l}66 \cdot 9 \pm 10 \cdot 3 \\
67 \cdot 5 \pm 13 \cdot 1 \\
65 \cdot 7 \pm 8 \cdot 7 \\
66 \cdot 6 \pm 10 \cdot 9\end{array}$ \\
\hline
\end{tabular}

Blood was collected into heparinized tubes via an indwelling venous catheter or by simple venepuncture. Plasma samples were deep frozen and stored for up to two weeks before analysis. After thawing plasma salicylic acid levels were estimated by the method of Saltzman (1948) with an Aminco-Bowman spectrofluorimeter. A control blood sample was collected by venepuncture in all cases before administration of the aspirin.

Control Subjects.-Preliminary studies in eight control subjects were used to establish the absorption profile for the aspirin preparation and to determine the effects of food and exercise upon this absorption (Volans, 1974). The peak salicylate levels were achieved within 60 minutes, and non-fasting subjects showed reduced absorption which was attenuated with time until after 60 minutes when the plasma levels were similar (see fig.). Moderate activity resulted in no significant changes in absorption compared with that at rest and there was no interaction between the effects of resting and non-resting and fasting and non-fasting on absorption. From these observations the control studies were extended to 20 subjects. Blood samples were collected at 30 and 60 minutes after ingestion of aspirin in the fasting state and after a standard breakfast. The subjects continued with their normal activities in the laboratory, clinic, or office.

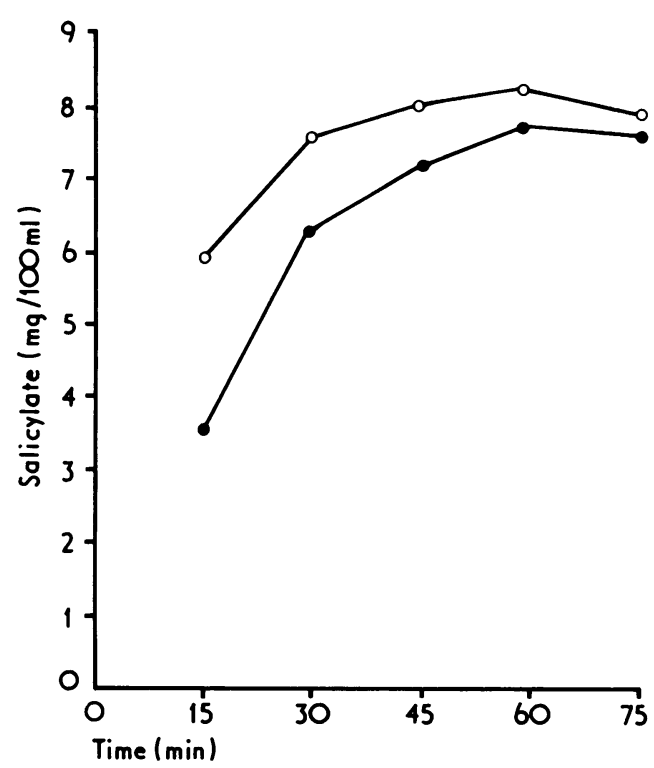

Mean plasma salicylate levels in eight subjects, fasting $(0)$ and non-fasting (O), after ingestion of $900 \mathrm{mg}$ aspirin from an effervescent formulation. (Reproduced by permission of the British fournal of Clinical Pharmacology.)

Patients.-Since the patients came into the clinic as emergencies it was not possible to control their food intake or their exercise before the study. The recorded history, therefore, included details of the duration of the attack before treatment and of the most recent food intake. Patients who had taken no food for more than four hours were considered to be fasting and the remainder were considered to be non-fasting. The severity of the headache and the gastrointestinal symptoms at the time of treatment were assessed by asking the patient whether the symptoms were slight, moderate, or severe as compared with his or her own experience of migraine attacks. During the study the patient lay on a couch in a darkened room. Movement was not restricted and visits to the toilet were permitted but the subject was not allowed to rest in the left lateral position as that position has been shown to reduce drug absorption (Martin 1971; Truitt and Morgan, 1964). Blood samples were collected at 30 minutes in all cases and also at 60 minutes in later studies. Some of the patients were studied also when they were headache free but under the same conditions.

\section{Results}

Comparison of Groups.-Since it was desirable to keep venepunctures to a minimum in patients suffering from migraine the earlier patients were studied at 30 minutes only after an ingestion of aspirin (migraine group 1; table I). When it became clear that some patients showed impaired absorption it was considered justifiable to extend the studies to 60 minutes in subsequent patients (migraine group 2). As this was the only criterion applied in the separation into two groups and since table I shows similar age and weight distributions in the two migraine groups the results in the migraine patients were combined in the following analysis.

Results in Fasting Subjects. - Thirty-five of the 42 patients were fasting at the time of the acute headache. The mean plasma salicylate levels achieved by these patients at 30 and 60 minutes after ingestion of effervescent aspirin with the levels achieved by the normal controls and by the patients who were studied when headache free are shown in table II. After 30 minutes the plasma salicylate levels during migraine were significantly lower than those found in normal controls $(t=4 \cdot 4$, $P<0.001)$. Taking as the criterion of poor absorption the lower $2 \frac{1}{2} \%$ confidence limit of plasma salicylate levels in normal controls-that is, $(4.42 \mathrm{mg} / 100 \mathrm{ml}), 16$ of the 35 patients were found to be "poor absorbers" during the migraine attack. Of these poor absorbers 14 were retested when headache-free, at which time the salicylate levels achieved were not significantly different from those found in normal controls $(t=1.09$, $P>0 \cdot 1)$. Absorption in these patients was, however, significantly impaired during the migraine attack (correlated $t=10.00$, $P<0.0001)$. After 60 minutes the plasma salicylate levels were studied in 18 patients. Again, the plasma salicylate levels achieved during migraine were significantly lower than those found in fasting normal controls $(t=3.02, \mathrm{P}<0.001)$. Nine of the patients who were poor absorbers at 30 minutes were retested when headache-free at 60 minutes. On that occasion the plasma salicylate levels again resembled those found in the normal controls $(t=0.92, \mathrm{P}>0 \cdot 1)$ though the patients had continued to show significant impairment of absorption during the migraine attack (correlated $t=2.20, \mathrm{P}<0.05$ ).

Results in Non-fasting Patients.-Only seven out of the 42 migraine patients were non-fasting at the time of investigation. This small number was considered insufficient for detailed statistical analysis, but when the 30-minute plasma salicylate levels were compared with the results from non-fasting normal controls (mean plasma salicylate $( \pm$ S.E.) $5 \cdot 18 \pm 0.37 \mathrm{mg} / 100$ $\mathrm{ml}$ ) three patients had plasma levels below the $2 \frac{1}{2} \%$ confidence limits (mean level for the three patients $1.64 \mathrm{mg} / 100 \mathrm{ml}$ ). When

TABLE II-Mean Plasma Salicylate Levels ( \pm S.E.) in Fasting Subjects after Ingestion of $900 \mathrm{mg}$ Effervescent Aspirin

\begin{tabular}{|c|c|c|c|}
\hline & $\begin{array}{c}\text { Migraine } \\
\text { Patients during } \\
\text { Attack }\end{array}$ & Controls & $\begin{array}{l}\text { Patient } \\
\text { Controls }\end{array}$ \\
\hline $\begin{array}{l}\text { No. of Subiects } \\
\text { Plasma salicylate }(\mathrm{mg} / \mathrm{i} 00 \mathrm{ml})\end{array}$ & \multirow{2}{*}{$\begin{array}{c}\text { After } 30 \text { Minutes } \\
35 \\
4.97 \pm 0.52 \\
\text { After } 60 \text { Minutes } \\
18 \\
6.63 \pm 0.30\end{array}$} & $\begin{array}{l}20 \\
7.88 \pm 0.40\end{array}$ & $7.11 \pm 0.59$ \\
\hline $\begin{array}{l}\text { No. of Subjects } \\
\text { Plasma salicylate }(\mathrm{mg} / 100 \mathrm{ml})\end{array}$ & & $\begin{array}{l}20 \\
8 \cdot 15 \pm 0 \cdot 29\end{array}$ & $\stackrel{9}{7.59 \pm 0.53}$ \\
\hline
\end{tabular}


TABLE III-Relationship of Sex, Diagnosis, and Migraine Symptoms to Quality of Absorption after 30 Minutes

\begin{tabular}{|c|c|c|c|c|c|c|c|c|c|c|c|c|c|c|}
\hline & \multicolumn{2}{|c|}{ Sex } & \multicolumn{2}{|c|}{ Diagnosis } & \multicolumn{3}{|c|}{ Severity of Headache } & \multicolumn{4}{|c|}{ Severity of Nausea } & \multicolumn{3}{|c|}{ Vomiting } \\
\hline & Male & Female & $\begin{array}{l}\text { Common } \\
\text { Migraine }\end{array}$ & $\begin{array}{l}\text { Classical } \\
\text { Migraine }\end{array}$ & Intense & Moderate & Slight & Intense & Moderate & Slight & None & $\begin{array}{c}<4 \mathrm{hr} \\
\text { before } \\
\text { Test }\end{array}$ & $\underset{\text { Test }}{\text { During }}$ & $\begin{array}{l}\text { After } \\
\text { Test }\end{array}$ \\
\hline $\begin{array}{l}\text { No. of poor absorbers } \ldots \\
\text { No. of good absorbers } .\end{array}$ & $\begin{array}{l}8 \\
9\end{array}$ & $\begin{array}{l}11 \\
14\end{array}$ & $\begin{array}{l}10 \\
12\end{array}$ & $\begin{array}{r}9 \\
11\end{array}$ & $\begin{array}{l}9 \\
4\end{array}$ & $\begin{array}{l}10 \\
11\end{array}$ & $\begin{array}{l}0 \\
8\end{array}$ & $\begin{array}{l}4 \\
2\end{array}$ & $\begin{array}{l}6 \\
1\end{array}$ & $\begin{array}{r}4 \\
10\end{array}$ & $\begin{array}{r}5 \\
10\end{array}$ & $\begin{array}{l}5 \\
2\end{array}$ & $\begin{array}{l}0 \\
1\end{array}$ & $\begin{array}{l}3 \\
0\end{array}$ \\
\hline Total .. & 17 & 25 & 22 & 20 & 13 & 21 & 8 & 6 & 7 & 14 & 15 & 7 & 1 & 3 \\
\hline Grand Total. . & \multicolumn{2}{|c|}{42} & \multicolumn{2}{|c|}{42} & \multicolumn{3}{|c|}{42} & \multicolumn{4}{|c|}{42} & \multicolumn{3}{|c|}{11} \\
\hline
\end{tabular}

these patients were retested under controlled conditions, which ncluded the taking of identical meals, they all achieved 30minute plasma salicylate levels well within the normal range (mean for the three patients $8.30 \mathrm{mg} / 100 \mathrm{ml}$ ).

Factors Affecting Absorption during Migraine Attacks.-From these results it can be seen that 19 out of 42 patients studied during migraine attacks showed absorption of effervescent aspirin which was below the $2 \frac{1}{2} \%$ confidence limit for normal subjects. This impairment of absorption was not shown, however, when the same subjects were retested under controlled headache-free conditions. To investigate the relationship of the clinical features to this impairment of absorption a number of other indices were assessed during the attack (table III). The poor absorbers were distributed almost equally between the two sexes and between cases of classical and common migraine. Poor absorption was found more frequently with increasing severity of headache (Kolmogorov-Smirnov two sample test $D$. $\max =0.348 ; P<0.05$ for one-tailed test). The association of increasing severity of nausea with poor absorption was also found to be significant (Kolmogorov-Smirnov two sample test D. $\max =0.396 ; P<0.03$ for one-tailed test). No patients with "slight headache" showed poor absorption while absorption was impaired in five out of 15 patients who denied feelings of nausea. Only 11 out of 42 patients vomited during the attacks which were studied and only one patient vomited during the absorption test. This subject must have retained most of the aspirin since normal salicylate levels were achieved. Of the remaining 10 subjects all vomited within four hours before the test and one hour after its completion. Eight of these were poor absorbers. All the cases in which absorption was impaired occurred during the first 15 hours of the attack, but there was no obvious correlation between the duration of the attack and the plasma salicylate level after 30 minutes (table IV).

TABLE IV-Relationship between Duration of Symptoms at Time of Treatment and Quality of Absorption after 30 Minutes. Results are Numbers of Patients

\begin{tabular}{|c|c|c|c|c|c|c|}
\hline \multicolumn{4}{|c|}{ Duration of Attack } & \multirow{2}{*}{$\begin{array}{c}\text { Poor Absorbers } \\
8 \\
7 \\
4 \\
0\end{array}$} & \multirow{2}{*}{$\begin{array}{c}\text { Good Absorbers } \\
11 \\
5 \\
3 \\
4\end{array}$} & \multirow{2}{*}{\begin{tabular}{r|} 
Total \\
19 \\
12 \\
7 \\
4
\end{tabular}} \\
\hline $\begin{array}{c}0-3 \mathrm{hr} \\
-6 \mathrm{hr} \\
-24 \mathrm{hr} \\
>24 \mathrm{hr}\end{array}$ & $\begin{array}{l}\cdots \\
\cdots \\
\cdots\end{array}$ & $\begin{array}{l}\cdots \\
\cdots \\
\cdots\end{array}$ & $\begin{array}{l}\cdots \\
\cdots \\
\cdots\end{array}$ & & & \\
\hline \multicolumn{4}{|c|}{ Total . . } & 19 & 23 & 42 \\
\hline
\end{tabular}

Response to Treatment with Effervescent Aspirin.-The response to treatment in these patients was not a direct concern of the present study. Nevertheless, preliminary examination of the clinical records showed that two-thirds of the patients improved without additional treatment. The patients who showed impaired absorption were more likely to have received further treatment than those who showed normal absorption. Furthermore, though the time taken to respond to treatment was probably influenced by many factors it does seem that the poor absorbers were slower to recover. It is hoped that full analysis of these and other records will provide information on the response to treatment, which will be discussed as a separate communication.

\section{Discussion}

Though gastrointestinal symptoms are recognized as an important feature of a migraine attack it is relatively unusual to find precise information about the incidence of such symptoms since most studies have been, not surprisingly, more concerned with the headache and its associated neurological symptoms. Lance and Anthony (1966), however, reported a series of 500 migraine patients referred to an outpatient clinic in which greater attention was paid to the gastrointestinal disturbance. They found that $16 \%$ experienced nausea, vomiting, and diarrhoea; $59 \%$ reported nausea and vomiting, and $18 \%$ noticed nausea only.

The patients included in the present study were attending as emergencies rather than for routine consultations and it was thought likely that the attacks studied would not represent the most severe attacks experienced by the same patients since at such times many feel unable to travel from their home or their work to the clinic. Evidence for this is seen in table $\mathrm{V}$ where it is shown that this group of patients has a similar overall incidence of gastrointestinal symptoms to that described by Lance and Anthony, but the incidence of symptoms at the time of the study was reduced by almost one-third. In spite of the tendency to under-represent the incidence of gastrointestinal symptoms in this study it was found that about $45 \%$ of the patients showed impairment of the rate of absorption of a drug which is normally rapidly absorbed. Since it was also shown that the same patients showed normal absorption when free from migraine symptoms it may be deduced that the impairment of absorption was a feature of the migraine attack.

TABLE V-Incidence of Gastrointestinal Symptoms in Migraine Attacks where Absorption was Studied compared with Incidence of Same Symptoms over all Attacks experienced by 42 Patients. Results are Percentages of Patients

\begin{tabular}{|c|c|c|c|}
\hline Symptom & & This Attack & All Attacks \\
\hline \begin{tabular}{lccc}
\multicolumn{3}{l}{ Nausea, Vomiting, and Diarrhoea. } \\
Nausea and Vomiting & $\ldots$ & $\ldots$ \\
Nausea Alone &. & $\ldots$ & $\ldots$ \\
\end{tabular} & $\begin{array}{l}\cdots \\
\cdots \\
\cdots\end{array}$ & $\begin{array}{l}12 \% \\
14 \% \\
38 \% \\
\end{array}$ & $\begin{array}{l}21 \% \\
48 \% \\
26 \% \\
\end{array}$ \\
\hline 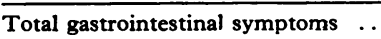 & $\ldots$ & $64 \%$ & $95 \%$ \\
\hline
\end{tabular}

Many of the symptoms of a migraine attack could be related to increased activity of the sympathetic nervous system (Sachs, 1970). Under such circumstances gastrointestinal motility would be reduced, and evidence for this has been found in radiological studies on patients suffering from acute migraine where delayed gastric emptying was shown, associated with either gastric dilatation (Kaufman and Levine, 1936) or prolonged gastric contraction (Kreel, 1973). Repeat studies when the patients were free from headache showed normally functioning stomachs.

Reduction of the rate of gastric emptying reduces the rate of paracetamol absorption (Nimmo et al., 1973), and though aspirin is absorbed from the stomach this route of absorption is relatively inefficient, most of the drug being absorbed from the small intestine (Martin, 1964). It is, therefore, most likely that delayed gastric emptying is the cause 
of the decreased absorption of aspirin which has been shown during the migraine attack. It is hoped to provide further evidence for this mechanism by absorption studies which are in progress to determine whether metoclopramide can overcome the decreased aspirin absorption during migraine attacks.

The finding of impaired gastrointestinal absorption of drugs during migraine attacks has a definite clinical significance. Most of the drugs used in acute migraine are less readily absorbed in normal individuals than effervescent aspirin and absorption of such drugs may be reduced to an even greater degree. Many migraine patients report that aspirin and paracetamol do not relieve their headaches. Since different formulations of aspirin (Martin, 1971) and paracetamol (Hedges and Kaye, 1973; Hedges et al., 1974) have very different rates of absorption the failure of response in migraine may often be related to the use of formulations which are slowly absorbed even in normal circumstances. To take account of impairment of drug absorption it is recommended that in the treatment of migraine preparations should be used which are rapidly absorbed or which bypass the gastrointestinal tract. In addition, the gastrointestinal symptoms should be noted and, if necessary, treated with antiemetics.

I thank the Migraine Trust for financing the research Fellowship which made this project possible and Dr. M. Wilkinson, Dr. G. Wainscott, Dr. J. Ide, and Mrs. M. C. Wall, my colleagues in the clinic, for their valuable help and advice. Pharmacological advice and criticism was given by Professor P. Turner and by Dr. R.
Renton of Nicholas Laboratories (who also arranged the supply of effervescent aspirin). The statistics are ultimately my responsibility but I thank Mr. D. Smith, Miss E. Fell, and Mrs. P. J. Volans for advice.

\section{References}

Critchley, M. (1967). In Background to Migraine, ed. R. Smith, p. 28.

London, Heinemann.
Graham, J. R., Malvea, B. P., and Gramm, H. F. (1960). New England Fournal of Medicine, 263, 802 .

Hedges, A., and Kaye, C. M. (1973). fournal of International Medical Research, $1,548$.

Hedges, A., et al. (1974). Fournal of Clinical Pharmacology. In press.

Kaufman, J., and Levine, I. (1936). Radiology, 27, 301.

Kreel, L. (1973). Postgraduate Medical fournal, 49, suppl. 4, p. 42.

Lance, J. W., and Anthony, M. (1966). Archives of Neurology, 15, 356.

Martin, B. K. (1964). In Absorption and Distribution of Drugs, ed. T. B. Binns, p. 165 . London, Livingstone.

Martin, B. K. (1971). In Advances in Pharmaceutical Sciences, ed. H. S. Bean, A. H. Beckett, and J. E. Carless, vol. 3, p. 107. Academia. London and New York.

Nimmo, J. (1973). Postgraduate Medical fournal, 49, Suppl. 4, p. 28.

Nimmo, J., et al. (1973). British Medical fournal, 1, 587.

Sachs, O. W. (1970). Migraine, Evolution of a Common Disorder, p. 194. London, Faber and Faber.

Saltzman, A. (1948). Fournal of Biological Chemistry, 174, 339.

Sutherland, J. M., and Eadie, M. J. (1961). Medical fournal of Australia, 48,740 .

Truitt, E. R., and Morgan, A. M. (1964). Fournal of Pharmaceutical Sciences, 53, 129 .

Volans, G. N. (1974). British fournal of Clinical Pharmacology, 1, 137. World Federation of Neurology (1970). In Background to Migraine, ed. Wilkinson, M. (1971). British Medical fournal, 2, 754

\title{
Host Resistance in Relation to Survival in Breast Cancer
}

\author{
MANUELE DI PAOLA, LICINIO ANGELINI, ANDREA BERTOLOTTI, SERGIO COLIZZA
}

British Medical fournal, 1974, 4, 268-270

\begin{abstract}
Summary
The degree of lymphocytic infiltration in and around breast tumours together with sinus histiocytosis and follicular hyperplasia in regional lymph nodes has been studied in 310 cases of breast cancer treated with standard radical mastectomy. The presence of these features was regarded as evidence of host resistance against the tumour and made possible the division of patients into three classes-no or poor reaction, good reaction, and strong reaction. The grading was shown to have a close correlation with prognosis. The relationship between host defensive factor grading and malignancy, nodal metastases, and survival was also examined. The results support the hypothesis that prognosis in breast cancer is closely related to a histological picture of cell-mediated immunity against the tumour.
\end{abstract}

\footnotetext{
Instituto Patologia Chirurgica II dell'Universita di Roma, Policlinico Umberto I', Roma, Italy

MANUELE DI PAOLA, M.D., Professor

LICINIO ANGELINI, M.D., Professor

ANDREA BERTOLOTTI, M.D., Professor

SERGIO COLIZZA, M.D., Research Fellow
}

\section{Introduction}

Among the factors thought to influence survival in cases of breast cancer treated surgically lymphocytic infiltration in and around the tumour and follicular hyperplasia and sinus histiocytosis in regional lymph nodes have received particular attention. These features have been regarded as evidence of an immunological response to the tumour but whether they correlate with a good prognosis is still open to controversy.

After the report of Foote and Stewart (1946) on lymphocytic infiltration of the stroma of medullary carcinoma the study was extended to regional lymph nodes (Black et al., 1953; Anastassiades and Pryce, 1966; Cutler et al., 1969; Wernicke, 1972), and a lymphocytic infiltration was found in all histological types of breast cancer (Hamlin, 1968,) particularly medullary carcinoma (Bloom et al., 1970).

Hamlin (1968) reviewed 272 cases of breast cancer and found a close correlation between prognosis and the intensity of lymphocytic infiltration around the tumour. In a study of 1,411 cases of breast cancer followed for 20 years Bloom et al. (1970) showed that the highly malignant medullary carcinoma carries a remarkably good prognosis when there is increased lymphocytic infiltration around the tumour. Recently increased benign lymphoid tissue in the lymph nodes of the apex of the axilla has been described as a favourable prognostic sign (Berg et al., 1973). Other workers, however, have found that sinus histiocytosis (Kister et al., 1969), follicular hyperplasia (Moore et al., 1960), and lymphocytic infiltration (Morrison et al., 1973) do not correlate with prognosis in breast cancer.

We have already made a preliminary report (Di Paola et al., 1973) of our findings in a limited number of cases of a relation- 